\title{
Influence of GRPR and BDNF/TrkB signaling on the viability of breast and gynecologic cancer cells
}

\author{
DANIELA B. CORNELIO ${ }^{1-3^{*}}$, CAROLINE B. DE FARIAS ${ }^{1-4^{*}}$, DÉBORA S. PRUSCH ${ }^{1-3}$, TIAGO E. HEINEN ${ }^{1-3}$, \\ RAFAEL P. DOS SANTOS ${ }^{1-3}$, ANA L. ABUJAMRA ${ }^{1-4}$, GILBERTO SCHWARTSMANN ${ }^{1,3,5}$ and RAFAEL ROESLER ${ }^{1-3}$ \\ ${ }^{1}$ Cancer Research Laboratory, University Hospital Research Center (CPE-HCPA); \\ ${ }^{2}$ Laboratory of Neuropharmacology and Neural Tumor Biology, Department of Pharmacology, \\ Institute for Basic Health Sciences, Federal University of Rio Grande do Sul; \\ ${ }^{3}$ National Institute for Translational Medicine (INCT-TM); \\ ${ }^{4}$ Children's Cancer Institute; ${ }^{5}$ Department of Internal Medicine, School of Medicine, \\ Federal University of Rio Grande do Sul, Porto Alegre, RS, Brazil
}

Received June 14, 2012; Accepted August 1, 2012

DOI: $10.3892 / \mathrm{mco} .2012 .7$

\begin{abstract}
Neuropeptide and neurotrophin receptors are increasingly important molecular targets in cancer. Scientific findings indicate that compounds blocking gastrin-releasing peptide receptors (GRPR) or tropomyosin receptor kinase (Trk) receptors are likely to have antiproliferative activities against cancer cells. The present study aimed to demonstrate that, in contrast to previous findings, GRPR activation reduces, whereas its blockade increases the viability of breast, ovarian and cervical cancer cell lines. However, consistent with previous studies, Trk inhibition was demonstrated to reduce the viability of these cells. MCF-7 (breast), OVCAR-3 (ovarian) and HeLa (cervical) human cancer cell lines were treated with GRP, the GRPR antagonists RC-3095 and RC-3940-II, brain-derived neurotrophic factor (BDNF) and the Trk antagonist K252 $\alpha$. Cell viability was measured by the MTT assay. Expression of GRPR and BDNF was confirmed with reverse transcription-polymerase chain reaction (RT-PCR). GRP reduced, whereas RC-3940-II enhanced the viability of the three cell lines. Treatment with $\mathrm{K} 252 \alpha$ inhibited the viability of the cell lines, while BDNF increased the viability of OVCAR-3 cells. The results supported the hypothesis that GRPR and BDNF/TrkB signaling regulates cancer cell viability. Most importantly, these findings are the first to demonstrate that GRPR blockade can stimulate, rather
\end{abstract}

Correspondence to: Dr Rafael Roesler, Department of Pharmacology, Institute for Basic Health Sciences, Federal University of Rio Grande do Sul, Rua Sarmento Leite, 500 (ICBS, Campus Centro/UFRGS), 90050-170 Porto Alegre, RS, Brazil

E-mail: rafael.roesler@pq.cnpq.br

${ }^{*}$ Contributed equally

Key words: gastrin-releasing peptide receptor, brain-derived neurotrophic factor, tropomyosin receptor kinase B, gynecologic cancer, cancer cell than inhibits the viability of breast and gynecologic cancer cell lines.

\section{Introduction}

Increasing evidence indicates that neuropeptide and neurotrophin receptors and their ligands may be overexpressed in cancer cells and are involved in cell survival and growth. Neuropeptide receptors aberrantly expressed in several human cancers include the gastrin-releasing peptide receptor (GRPR), activated in mammals by the bombesin-like neuropeptide gastrin-releasing peptide (GRP). GRPR activation has been shown to stimulate cancer cell proliferation, whereas GRPR antagonists to reduce tumor growth in a range of experimental cancer models $(1,2)$. In gynecologic cancers, GRPR is likely to be highly expressed in breast, ovarian and cervical tumors, as well as in breast cancer cell lines, whereas its expression is low or absent in non-neoplastic tissue and healthy cells (1,3-8). The pharmacological blockade of GRPR by synthetic peptides acting as selective antagonists (RC-3940-II, RC-3095) has been shown to reduce human breast and ovarian tumor growth xenografted into nude mice (9-11).

Additional growth factor receptors increasingly implicated in tumor progression include tropomyosin receptor kinase (Trk) receptors. Trks are receptor tyrosine kinases activated endogenously by neurotrophins. TrkA, TrkB and TrkC are the preferred receptors for nerve growth factor (NGF), brain-derived neurotrophic factor (BDNF) and neurotrophin-3 (NT-3), respectively (12). Increased BDNF and TrkB expressions have recently been found in several human tumors (13-15). BDNF/TrkB promote cancer cell survival and resistance to chemotherapy, while small-molecule inhibitors of Trk, such as K252 $\alpha$, inhibit cell growth and induce apoptotic death in cancer cells (16-19). TrkB expression has been described in ovarian and cervical cancers $(20,21)$, while being associated with a shorter survival and the promotion of metastasis in ovarian cancer patients (20). In addition, studies using ovarian cancer cells indicated that TrkB is involved 
in cell proliferation, migration and suppression of anoikis $(22,23)$. In breast cancer, BDNF expression has been shown to be higher in tumor samples compared to non-neoplastic tissues, while BDNF transcript levels have been associated with unfavorable pathological parameters and adverse clinical outcomes (24). Moreover, BDNF has been shown to induce resistance to apoptosis in breast cancer cells, while injection of an anti-BDNF antibody has been proven to reduce the growth of breast tumors xenografted in mice (25).

The present study aimed to explore the effects of GRPR and TrkB ligands on the viability of human breast, ovarian and cervical cancer cells in vitro. Notably, under the experimental conditions used in this study, GRP produced a small, but statistically significant reduction of cell viability, whereas the RC-3940-II-induced GRPR blockade led to a statistically significant increase in cell viability. In addition, $\mathrm{K} 252 \alpha$-induced Trk inhibition was found to have reduced cell viability.

\section{Materials and methods}

Cell culture andtreatments.MCF-7,OVCAR-3 and HeLa human cells were obtained from the American Type Culture Collection (Rockville, MD, USA). The cells were plated in 96-well plates (TPP) at a density of 4,7 and $3 \times 10^{3}$ cells/well in sextuplets, respectively, and then cultured and maintained in Dulbecco's modified Eagle's medium (DMEM; Gibco-BRL, Carlsbad, CA, USA) (MCF-7 and HeLa cells) and RPMI-1640 (Gibco-BRL) (OVCAR-3 cells), containing 2\% (w/v) LH-glutamine and $10 \%$ (v/v) fetal bovine serum (FBS; Sorali, Campo Grande, Brazil). For the experiments GRP treatment was used, whereby cells were starved for $24 \mathrm{~h}$ in medium supplemented with $0.5 \%$ serum medium and then treated with human recombinant GRP (0.001, 0.01, 0.1, 1 or $10 \mu \mathrm{M}$; Sigma-Aldrich, St. Louis, MO, USA). For other treatments, $24 \mathrm{~h}$ after medium and serum addition, the cells were treated with the GRPR antagonist [D-Tpi ${ }^{6}$, $\left.\mathrm{Leu}^{13} \mathrm{psi}\left(\mathrm{CH}_{2} \mathrm{NH}\right)-\mathrm{Leu}^{14}\right]$ bombesin (RC-3095; 0.001, 0.01, $0.1,1$ or $10 \mu \mathrm{M}$; Zentaris GmbH, Frankfurt, Germany), the GRPR antagonist $\left[\mathrm{Hca}^{6}, \mathrm{Leu}^{13} \mathrm{psi}\left(\mathrm{CH}_{2} \mathrm{~N}\right)\right.$-Tac14-bombesin $\left.{ }^{6-14}\right]$ (RC-3940-II; 0.01, 0.1, 0.5, 1 or $5 \mu \mathrm{M}$; Zentaris $\mathrm{GmbH}$ ) (10), human recombinant BDNF (1, 10 or $100 \mathrm{ng} / \mathrm{ml}$; Sigma-Aldrich) or $\mathrm{K} 252 \alpha(0.01,0.1$ or $1 \mu \mathrm{M}$, Sigma-Aldrich). The cells were kept at a temperature of $37^{\circ} \mathrm{C}$, in a minimum relative humidity of $95 \%$ and an atmosphere of $5 \% \mathrm{CO}_{2}$ in air.

MTT assay. The cell viability was measured using 3-(4,5-dimethylthiazol-2-yl)-2,5-diphenyl tetrazolium bromide (MTT; Sigma-Aldrich) 48 h subsequent to treatment. Eleven microliters of MTT $5 \mathrm{mg} / \mathrm{ml}$ solution were added to each well of the plate, followed by incubation for $4 \mathrm{~h}$ at $37^{\circ} \mathrm{C}$. The plate was left at room temperature until completely dry. Dimethyl sulfoxide was added and the absorbance was measured at $492 \mathrm{~nm}$ in a multiplate reader. The experiments were performed at least in triplicate.

Reverse transcription-polymerase chain reaction (RT-PCR). Total RNA was extracted from MCF-7, OVCAR-3 and HeLa cells using TRIzol reagent (Invitrogen, Carlsbad, CA, USA), in accordance with the manufacturer's instructions, and reverse transcribed with SuperScript ${ }^{\circledR}$ III First-Strand Synthesis SuperMix ${ }^{\circledR}$ (Invitrogen). The human BDNF and
GRPR primers were designed according to the corresponding GenBank sequence. The forward and reverse primers used for RT-PCR amplification are shown in Table I. The PCR experiments were carried out with $1.5 \mathrm{mM} \mathrm{MgCl}_{2}, 0.1 \mu \mathrm{M}$ for each primer, $0.2 \mathrm{mM}$ dNTPs, $0.5 \mathrm{M}$ betain (only to BDNF primers), 1 unit Taq Platinum ${ }^{\circledR}$ (Invitrogen) and $2 \mu \mathrm{l}$ cDNA template. The expression of $\beta$-actin was measured as an internal control using the primers shown in Table I. The PCR reaction was performed in a total volume of $20 \mu \mathrm{l}$ using a concentration of $0.04 \mathrm{mM}$ dNTPs, 0.2 units Taq polymerase in the supplied reaction buffer, $0.3 \mathrm{mM} \mathrm{MgCl}_{2}$ and $10 \mathrm{pmol}$ of each primer. Amplification conditions consisted of $1 \mathrm{~min}$ at $95^{\circ} \mathrm{C}$ followed by 35 cycles of denaturation at $94^{\circ} \mathrm{C}$ for $30 \mathrm{sec}$, annealing at $59^{\circ} \mathrm{C}$ for $30 \mathrm{sec}$, extension of primers at $72^{\circ} \mathrm{C}$ for $45 \mathrm{sec}$, followed by a final extension at $72^{\circ} \mathrm{C}$ for $10 \mathrm{~min}$. The products of BDNF (362 bp), GRPR (190 bp) and $\beta$-actin (190 bp) were electrophoresed through $2 \%$ agarose gels, stained with ethidium bromide and visualized under ultraviolet illumination $(17,26,27)$. Each experiment was performed twice using RNA isolated from two independent cell cultures.

Statistical analysis. Data were shown as the mean \pm SEM. Differences between the mean values were evaluated by one-way analysis of variance followed by Tukey post hoc tests, when appropriate. In the comparisons, $\mathrm{P}<0.05$ was considered to indicate a statistically significant difference.

\section{Results}

GRPR activation reduced, whereas GRPR blockade increased the viability of MCF-7, OVCAR-3 and HeLa cells. Treatment with recombinant GRP induced a small (range, 11.3-36.0\%), yet statistically significant reduction of cell viability in the three cell lines studied (Fig. 1A). Viability was reduced by GRP at all the doses used in MCF-7 cells, with the exception of $0.001 \mu \mathrm{M}$ in OVCAR-3 cells and only at $1 \mu \mathrm{M}$ in HeLa cells (Fig. 1B). The GRPR antagonist RC-3940-II led to increases ranging from 200.1 to $476.8 \%$ in the viability of all three cell lines, at all doses used, with the exception of the $0.01 \mu \mathrm{M}$ in OVCAR-3 and the $5 \mu \mathrm{M}$ in HeLa cells. The less potent (10) GRPR antagonist RC-3095 demonstrated an increase of $\sim 24 \%$ in the viability of OVCAR-3 cells, however, no statistically significant effect was observed in OVCAR-3 or HeLa cells (Fig. 1C). Given these negative findings, RC-3095 in MCF-7 cells was not tested. These results indicated that GRPR activation reduced, whereas GRPR blockade increased the viability of MCF-7, OVCAR-3 and HeLa cells.

Trk inhibition reduced the viability of MCF-7, OVCAR-3 and HeLa cells. Treatment with BDNF had no significant effect on cell viability, except for a small effect at a dose of $1 \mathrm{ng} / \mathrm{ml}$ in OVCAR-3 cells (Fig. 2A). The Trk inhibitor K252 $\alpha$ demonstrated a notable inhibitory effect on cell viability (ranging from 13.5 to $44.6 \%$ ), at a dose of $1 \mu \mathrm{M}$ in the three cell lines, and at a dose of $0.01 \mu \mathrm{M}$ in MCF-7 cells (Fig. 2B). These results indicated that Trk inhibition reduced the viability of MCF-7, OVCAR-3 and HeLa cells in a dose-dependent manner.

GRPR and BDNF expression in MCF-7, OVCAR-3 and HeLa cells. RT-PCR analyses demonstrated that MCF-7, 
Table I. Forward and reverse primers used for RT-PCR amplification.

\begin{tabular}{llr}
\hline Gene & \multicolumn{1}{c}{ Primer sequences } & PCR product size (bp) \\
\hline GRPR & Forward: 5'-CAAGATCTTCTGCACGGTCA-3' & 190 \\
& Reverse: 5'-TCAGTTTGCAGCCAATTCTG-3' & 362 \\
BDNF & Forward: 5'-GCGTGAATGGGCCCAAGGCAGG-3' & 190 \\
& Reverse: 5'-TGTGACCGTCCCGCCCGACATG-3' & Forward: 5'-AAACTGGAACGGTGAAGGTG-3' \\
& Reverse: 5'-AGAGAAGTGGGGTGGCTTTT-3'
\end{tabular}

$\mathbf{A}$

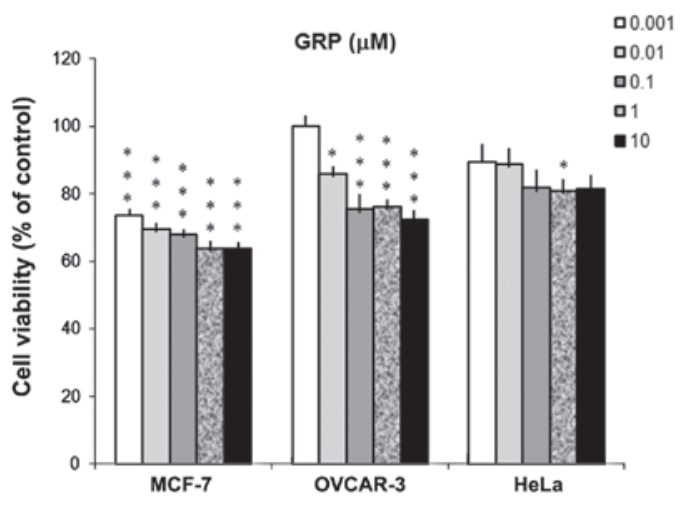

B
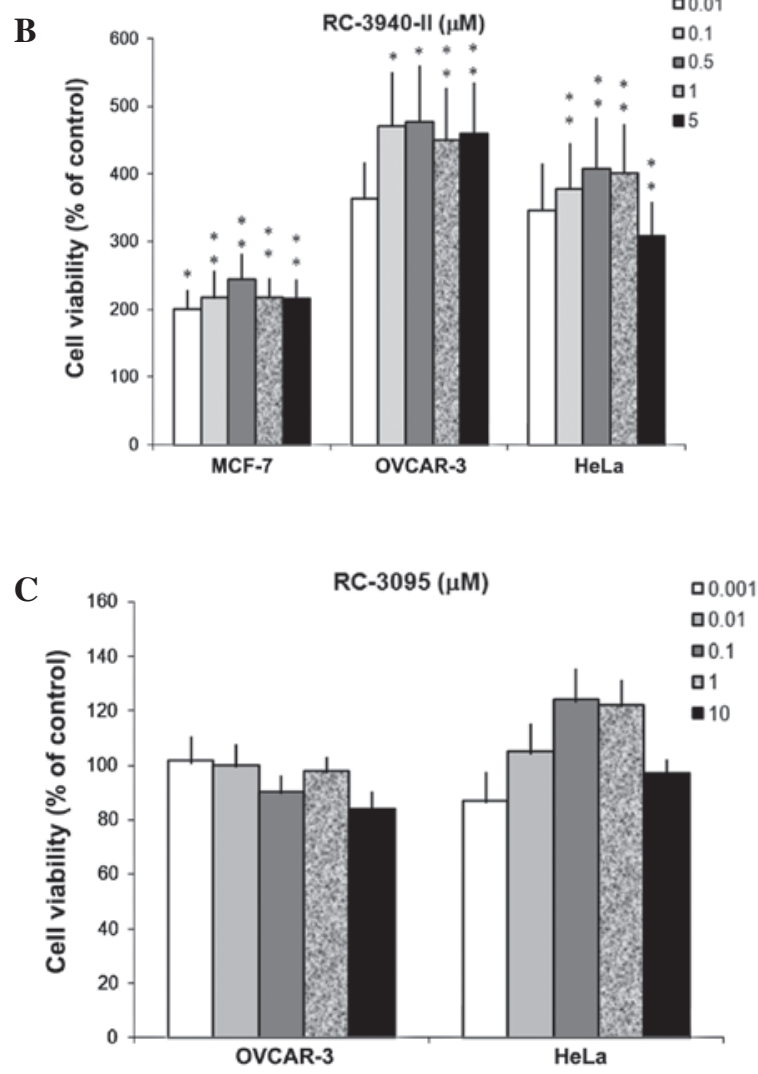

Figure 1. A GRPR agonist reduces, whereas a GRPR antagonist increases the viability of human breast, ovarian and cervical cancer cell lines in vitro. MCF-7, OVCAR-3 and HeLa cells were treated with (A) human recombinant GRP $(0.001,0.01,0.1,1$ or $10 \mu \mathrm{M})$; (B) RC-3940-II $(0.01,0.1,0.5,1$ or $5 \mu \mathrm{M})$ and (C) RC-3095 $(0.001,0.01,0.1,1$ or $10 \mu \mathrm{M})$. RC-3095 was tested in OVCAR-3 and HeLa cells only. Cell viability was measured using an MTT assay, as described in Materials and methods. Data are the mean \pm SEM of 3-5 different experiments performed in 4-6 wells each. The mean value for the control cells was taken as $100 \% ;{ }^{*} \mathrm{P}<0.05,{ }^{* *} \mathrm{P}<0.01$ and ${ }^{* * * *} \mathrm{P}<0.001$ compared to control cells
A

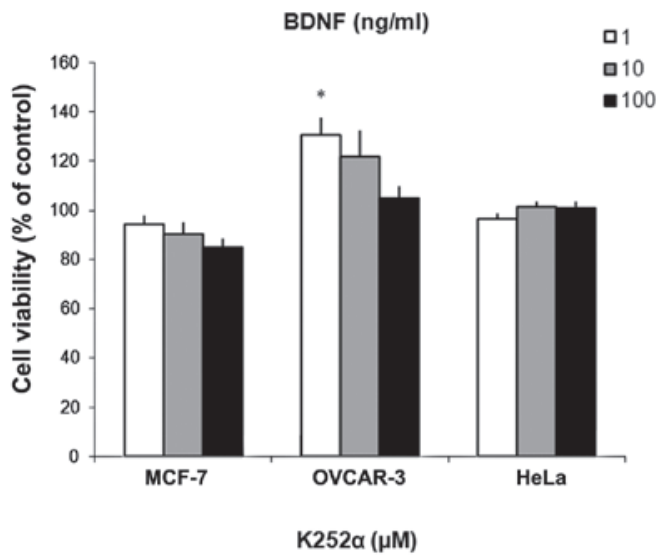

B

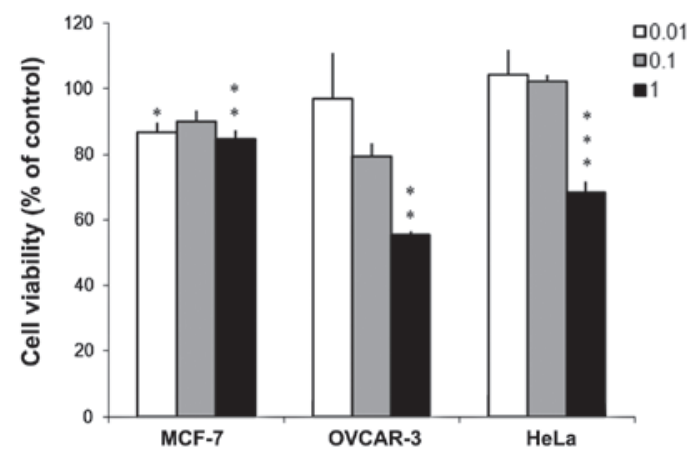

Figure 2. Trk inhibition reduces the viability of human breast, ovarian and cervical cancer cell lines in vitro. MCF-7, OVCAR-3 and HeLa cells were treated with (A) human recombinant BDNF (1, 10 or $100 \mathrm{ng} / \mathrm{ml}$ ) or (B) $\mathrm{K} 252 \alpha$ RC-3940-II $(0.01,0.1$ or $1 \mu \mathrm{M})$. Cell viability was measured using an MTT assay, as described in Materials and methods. Data are the mean \pm SEM of 3-4 different experiments performed in 4-6 wells each. The mean value for the control cells was taken as $100 \%$; ${ }^{*} \mathrm{P}<0.05$ and ${ }^{* * *} \mathrm{P}<0.001$ compared to the control cells.

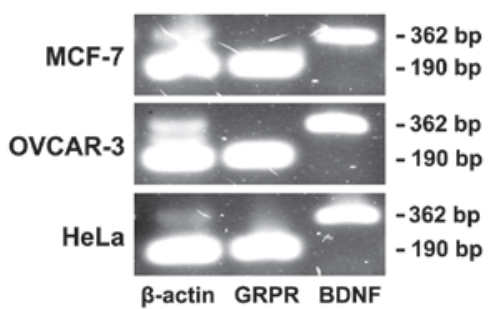

Figure 3. RT-PCR analysis of GRPR and BDNF mRNA expression in MCF-7, OVCAR-3 and HeLa human cancer cells is shown. RNA was extracted from the cells and RT-PCR analysis was performed, as described in Materials and methods. Transcript sizes of 190 and 362 bp were identified, representing fragments of GRPR and BDNF, respectively. 
VCAR-3 and HeLa cells showed an mRNA expression for both GRPR and BDNF. Transcript sizes of 190 and 362 bp, representing fragments of GRPR and BDNF, respectively, were identified in the cells (Fig. 3).

\section{Discussion}

The most important finding of the present study is that, in contrast to findings of previous studies $(1,2,9-11)$, pharmacological blockade of the GRPR exhibited an enhancing, rather than an inhibitory action on cancer cells, whereas GRP decreased cell viability. In addition, Trk inhibition was found to reduce the viability of the breast, ovarian and cervical cancer cell lines used, although treatment with BDNF did not alter cell viability.

GRPR antagonists have been previously shown to reduce experimental breast and ovarian tumor growth in vivo (9-11). However, the effects of the GRPR agonists and antagonists on cancer cell growth depends markedly on specific cell culture and experimental conditions. Consistent with these hypotheses, Yano et al (28) found that bombesin (showing a GRPR agonistic action comparable to that of GRP) at doses ranging from 0.001 to $1 \mu \mathrm{M}$ stimulated, while RC-3095 at doses between 0.01 and $10 \mu \mathrm{M}$ inhibited the proliferation of human breast cancer cell lines only when cells were cultured in heat-inactivated and dextran-coated charcoal-treated FBS (DCC-FBS), but not in the presence of untreated FBS. Additionally, MCF-7 cells failed to respond to bombesin or RC-3095 in the presence of either FBS or DCC-FBS. The authors of that study suggested that bombesin-like peptides or other growth factors present in the culture medium may compete with GRPR ligands, thus altering the cell response to the treatments. Authors of other studies (29) found that bombesin failed to affect MCF-7 cell proliferation, although the cells expressed GRP binding sites, while bombesin stimulated calcium mobilization and inositol lipid hydrolysis. Discrepancies among different studies might be due to differences in cell clones, cell culture conditions and methods used to assess proliferation and viability (e.g., trypan blue dye exclusion vs. MTT) in different laboratories.

In a previous study using Neuro2A mouse neuroblastoma cells, a lower dose of RC-3095 was found to reduce, while a higher dose to increase cell viability (30). Notably, in experiments examining cancer cell growth $(27,30,31)$, as well as in other experimental models (32-34), GRPR agonists and antagonists often show drug-response patterns, in which intermediate doses have more pronounced biological, whereas higher doses have no or even contrary effects. Moreover, the lack of a significant effect of RC-3095 in the present study might be owed to its lower potency compared to RC-3940-II. The latter has been shown to inhibit cancer cell proliferation at lower dose ranges, and was more effective compared to RC-3095, in inhibiting experimental breast cancer cell growth (10). Taken together, these data raise the possibility that GRPR agonists and antagonists have highly varying effects depending on the dose and the presence of endogenous GRP, as well as other factors in the tissue microenvironment, with potential implications of their effects in vivo in both experimental animals and patients undergoing clinical studies.
Although several molecular mechanisms downstream of GRPR activation have been described and proposed to mediate GRPR-induced cancer cell growth regulation, the mechanisms underlying the stimulatory effects of GRPR blockade on cancer cells observed in the present study and previous experiments (30) remain unknown and have yet to be investigated in future studies. Cell responses to GRPR activation are mediated by multiple protein kinase pathways, including phospholipase $\mathrm{C}$ (PLC)/protein kinase C (PKC), mitogen-activated protein kinase (MAPK)/extracellular signal-regulated protein kinase (ERK) and phosphatidylinositol 3-kinase (PI3K) cascades (35). Studies focusing on experimental breast and gynecologic cancers have demonstrated that GRPR is associated with cell migration and interleukin-8 expression in breast tumors (36), whereas GRPR antagonists reduce ErbB-2/HER-2 expression in breast cancer cells and epidermal growth factor receptor (EGFR), as well as c-jun and c-fos oncogenes in experimental breast and ovarian tumors $(9,11,38)$.

$\mathrm{BDNF} /$ TrkB signaling has been suggested to promote cancer cell survival and resistance to chemotherapy (12-14). Previous studies on breast and ovarian cancer cells have suggested that BDNF/TrkB stimulates cell survival and migration $(20,22,23,25)$. BDNF is likely not to enhance viability since the BDNF/TrkB pathway is already activated at its optimal level by BDNF secreted from the cells as an autocrine factor. The possibility that BDNF is secreted as an autocrine factor from cultured cells would be consistent with our finding that the three cell lines expressed mRNA for BDNF. Results of this study demonstrating that K252 $\alpha$ decreased cell viability are consistent with the hypothesis that TrkB needs to be further examined as a potential anticancer target in breast and gynecologic cancers. Since TrkB has the potential to crosstalk with GRPR and other growth factor receptors, including EGFR, in regulating cancer cell survival and proliferation (17,22), combining compounds acting on different receptors might prove to be the most effective strategy to inhibit tumor growth by targeting neuropeptide and neurotrophin signaling.

In conclusion, the present study is the first to demonstrate that, at least under certain experimental conditions, GRPR activation negatively regulates the viability of breast, ovarian and cervical cancer cells in vitro. In addition, these findings are consistent with the hypothesis that Trk signaling regulates the viability of breast and gynecologic cancer cells. Experimental findings suggesting that there are conditions under which GRPR blockade stimulates cell viability and proliferation are likely to have implications for the clinical testing of GRPR antagonists as potential anticancer medications. Based on the in vitro findings reported in this study, additional studies using in vivo models and tumor samples from patients are required in order to examine the potential inhibitory role of GRPR activation in breast and gynecologic cancer development.

\section{Acknowledgements}

This study was financed by the National Council for Scientific and Technological Development (CNPq; no. 303703/2009-1 to R.R); the National Institute for Translational Medicine (INCT-TM); FAPERGS/CNPq grant no. 10/0044-3-PRONEX; the University Hospital Research Fund (FIPE/HCPA); the 
South American Office for Anticancer Drug Development and the Children's Cancer Institute (ICI-RS).

\section{References}

1. Cornelio DB, Roesler R and Schwartsmann G: Gastrin-releasing peptide receptor as a molecular target in experimental anticancer therapy. Ann Oncol 18: 1457-1466, 2007.

2. Patel O, Shulkes A and Baldwin GS: Gastrin-releasing peptide and cancer. Biochim Biophys Acta 1766: 23-41, 2006.

3. Cornelio DB, Meurer L, Roesler R and Schwartsmann G: Gastrin-releasing peptide receptor expression in cervical cancer. Oncology 73: 340-345, 2007.

4. Cornelio DB, Meurer L, Schwartsmann G and Roesler R: The gastrin-releasing peptide receptor as a marker of dysplastic alterations in cervical epithelial cells. Oncology 82: 90-97, 2012

5. Giacchetti S, Gauvillé C, de Crémoux P, et al: Characterization, in some human breast cancer cell lines, of gastrin-releasing peptide-like receptors which are absent in normal breast epithelial cells. Int J Cancer 46: 293-298, 1990.

6. Gugger M and Reubi JC: Gastrin-releasing peptide receptors in non-neoplastic and neoplastic human breast. Am J Pathol 155: 2067-2076, 1999.

7. Halmos G, Wittliff JL and Schally AV: Characterization of bombesin/gastrin-releasing peptide receptors in human breast cancer and their relationship to steroid receptor expression. Cancer Res 55: 280-287, 1995.

8. Sun B, Schally AV and Halmos G: The presence of receptors for bombesin/GRP and mRNA for three receptor subtypes in human ovarian epithelial cancers. Regul Pept 90: 77-84, 2000.

9. Chatzistamou I, Schally AV, Szepeshazi K, et al: Inhibition of growth of ES-2 human ovarian cancers by bombesin antagonist RC-3095, and luteinizing hormone-releasing hormone antagonist Cetrorelix. Cancer Lett 171: 37-45, 2001.

10. Miyazaki M, Lamharzi N, Schally AV, et al: Inhibition of growth of MDA-MB-231 human breast cancer xenografts in nude mice by bombesin/gastrin-releasing peptide (GRP) antagonists RC-3940-II and RC-3095. Eur J Cancer 34: 710-717, 1998.

11. Yano T, Pinski J, Szepeshazi K, et al: Inhibitory effect of bombesin/gastrin-releasing peptide antagonist RC-3095 and luteinizing hormone-releasing hormone antagonist SB-75 on the growth of MCF-7 MIII human breast cancer xenografts in athymic nude mice. Cancer 73: 1229-1238, 1994

12. Huang EJ and Reichardt LF: Trk receptors: roles in neuronal signal transduction. Annu Rev Biochem 72: 609-642, 2003.

13. Desmet CJ and Peeper DS: The neurotrophic receptor TrkB: a drug target in anti-cancer therapy? Cell Mol Life Sci 63: 755-759, 2006.

14. Roesler R, de Farias CB, Abujamra AL, Brunetto AL and Schwartsmann G: BDNF/TrkB signaling as an anti-tumor target. Expert Rev Anticancer Ther 11: 1473-1475, 2011

15. Thiele CJ, Li Z and McKee AE: On Trk - the TrkB signal transduction pathway is an increasingly important target in cancer biology. Clin Cancer Res 15: 5962-5967, 2009.

16. Akil H, Perraud A, Mélin C, Jauberteau MO and Mathonnet M: Fine-tuning roles of endogenous brain-derived neurotrophic factor, TrkB and sortilin in colorectal cancer cell survival. PLoS One 6: e25097, 2011.

17. de Farias CB, Rosemberg DB, Heinen TE, et al: BDNF/TrkB content and interaction with gastrin-releasing peptide receptor blockade in colorectal cancer. Oncology 79: 430-439, 2010.

18. Li Z, Oh DY, Nakamura K and Thiele CJ: Perifosine-induced inhibition of Akt attenuates brain-derived neurotrophic factor/TrkB-induced chemoresistance in neuroblastoma in vivo. Cancer 117: 5412-5422, 2011.

19. Perez-Pinera P, Hernandez T, García-Suárez O, et al: The Trk tyrosine kinase inhibitor K252 $\alpha$ regulates growth of lung adenocarcinomas. Mol Cell Biochem 295: 19-26, 2007.

20. Au CW, Siu MK, Liao X, et al: Tyrosine kinase B receptor and BDNF expression in ovarian cancers - effect on cell migration, angiogenesis and clinical outcome. Cancer Lett 281: 151-161, 2009.
21. Moon A, Won KY, Lee JY, et al: Expression of BDNF, TrkB, and p53 in early-stage squamous cell carcinoma of the uterine cervix. Pathology 43: 453-458, 2011.

22. Qiu L, Zhou C, Sun Y, et al: Crosstalk between EGFR and TrkB enhances ovarian cancer cell migration and proliferation. Int $\mathrm{J}$ Oncol 29: 1003-1011, 2006.

23. Yu X, Liu L, Cai B, He Y and Wan X: Suppression of anoikis by the neurotrophic receptor TrkB in human ovarian cancer. Cancer Sci 99: 543-552, 2008

24. Patani N, Jiang WG and Mokbel K: Brain-derived neurotrophic factor expression predicts adverse pathological and clinical outcomes in human breast cancer. Cancer Cell Int 11: 23, 2011.

25. Vanhecke E, Adriaenssens E, Verbeke S, et al: Brain-derived neurotrophic factor and neurotrophin- $4 / 5$ are expressed in breast cancer and can be targeted to inhibit tumor cell survival. Clin Cancer Res 17: 1741-1752, 2011.

26. de Farias CB, Lima RC, Lima LO, et al: Stimulation of proliferation of U138-MG glioblastoma cells by gastrin-releasing peptide in combination with agents that enhance cAMP signaling. Oncology 75: 27-31, 2008 .

27. Flores DG, de Farias CB, Leites J, et al: Gastrin-releasing peptide receptors regulate proliferation of C6 Glioma cells through a phosphatidylinositol 3-kinase-dependent mechanism. Curr Neurovasc Res 5: 99-105, 2008

28. Yano T, Pinski J, Groot K and Schally AV: Stimulation by bombesin and inhibition by bombesin/gastrin-releasing peptide antagonist RC-3095 of growth of human breast cancer cell lines. Cancer Res 52: 4545-4547, 1992.

29. Patel KV and Schrey MP: Activation of inositol phospholipid signaling and $\mathrm{Ca}^{2+}$ efflux in human breast cancer cells by bombesin. Cancer Res 50: 235-239, 1990.

30. Abujamra AL, Almeida VR, Brunetto AL, Schwartsmann G and Roesler R: A gastrin-releasing peptide receptor antagonist stimulates Neuro2 $\alpha$ neuroblastoma cell growth: prevention by a histone deacetylase inhibitor. Cell Biol Int 33: 899-903, 2009.

31. Pinski J, Schally AV, Halmos G, et al: Somatostatin analogues and bombesin/gastrin-releasing peptide antagonist RC-3095 inhibit the growth of human glioblastomas in vitro and in vivo. Cancer Res 54: 5895-5901, 1994

32. Czepielewski RS, Porto BN, Rizzo LB, et al: Gastrin-releasing peptide receptor (GRPR) mediates chemotaxis in neutrophils. Proc Natl Acad Sci USA 109: 547-552, 2012

33. Roesler R, Luft T, Oliveira SH, et al: Molecular mechanisms mediating gastrin-releasing peptide receptor modulation of memory consolidation in the hippocampus. Neuropharmacology 51: 350-357, 2006.

34. Roesler R, Meller CA, Kopschina MI, et al: Intrahippocampal infusion of the bombesin/gastrin-releasing peptide antagonist RC-3095 impairs inhibitory avoidance retention. Peptides 24: 1069-1074, 2003

35. Jensen RT, Battey JF, Spindel ER and Benya RV: International Union of Pharmacology. LXVIII. Mammalian bombesin receptors: nomenclature, distribution, pharmacology, signaling, and functions in normal and disease states. Pharmacol Rev 60 $1-42,2008$.

36. Chao C, Ives K, Hellmich HL, Townsend CM Jr and Hellmich MR: Gastrin-releasing peptide receptor in breast cancer mediates cellular migration and interleukin-8 expression. J Surg Res 156: 26-31, 2009.

37. Bajo AM, Schally AV, Krupa M, et al: Bombesin antagonists inhibit growth of MDA-MB-435 estrogen-independent breast cancers and decrease the expression of the ErbB-2/HER-2 oncoprotein and c-jun and c-fos oncogenes. Proc Natl Acad Sci USA 99: 3836-3841, 2002.

38. Chatzistamou I, Schally AV, Sun B, Armatis P and Szepeshazi K: Inhibition of growth of OV-1063 human epithelial ovarian cancers and c-jun and c-fos oncogene expression by bombesin antagonists. Br J Cancer 83: 906-913, 2000. 